\title{
UV-induced carbon monoxide emission from living vegetation
}

\author{
D. Bruhn ${ }^{1,2}$, K. R. Albert ${ }^{1}$, T. N. Mikkelsen ${ }^{1}$, and P. Ambus ${ }^{1}$ \\ ${ }^{1}$ Department of Chemical and Biochemical Engineering, Technical University of Denmark (DTU), \\ 2800 Kgs. Lyngby, Denmark \\ ${ }^{2}$ Centre for Earth, Planetary, Space and Astronomical Research, The Open University, Walton Hall, \\ Milton Keynes MK76AA, UK \\ Correspondence to: D. Bruhn (dan.bruhn@open.ac.uk)
}

Received: 20 May 2013 - Published in Biogeosciences Discuss.: 12 June 2013

Revised: 23 October 2013 - Accepted: 1 November 2013 - Published: 3 December 2013

\begin{abstract}
The global burden of carbon monoxide (CO) is rather uncertain. In this paper we address the potential for UV-induced $\mathrm{CO}$ emission by living terrestrial vegetation surfaces. Real-time measurements of $\mathrm{CO}$ concentrations were made with a cavity-enhanced laser spectrometer connected in closed loop to either a chamber on a field of grass or a plant-leaf scale chamber. Leaves of all plant species that were examined exhibited emission of $\mathrm{CO}$ in response to artificial UV radiation as well as the UV component of natural solar radiation. The UV-induced rate of $\mathrm{CO}$ emission exhibited a low dependence on temperature, indicating an abiotic process. The emission of CO in response to the UV component of natural solar radiation was also evident at the natural grassland scale.
\end{abstract}

\section{Introduction}

Carbon monoxide (CO) is a reactive gas which, in part, controls the oxidizing capacity of the atmosphere (IPCC, 2001). Carbon monoxide can lead to the formation of ozone $\left(\mathrm{O}_{3}\right)$, and since $\mathrm{CO}$ is a main reactant of hydroxyl $(\mathrm{OH})$ radicals, which are the principal sink for atmospheric methane $\left(\mathrm{CH}_{4}\right), \mathrm{CO}$ also indirectly affects the atmospheric $\mathrm{CH}_{4}$ levels (IPCC, 2001). Carbon monoxide is therefore an important trace gas in the atmosphere (IPCC, 2001). Estimated total global source strengths and estimated total sink strengths are very similar (IPCC, 2001), but large uncertainties remain about the strength of the individual natural terrestrial direct sources (Potter et al., 1996; Guenther, 2002), which adds a great uncertainty to estimates of the net $\mathrm{CO}$ burden (360 Tg CO yr ${ }^{-1}$, IPCC, 2001).
All natural terrestrial direct $\mathrm{CO}$ emissions, in the range of 50-200 $\mathrm{Tg} \mathrm{CO} \mathrm{yr}^{-1}$, have hitherto been ascribed by the IPCC $(1995,2001)$ to photo-induced CO emission by living plants (cf. Tarr et al., 1995). However, in the studies underlying the photo-induced $\mathrm{CO}$ emission by living plants, which were incorporated into previous global CO budgets (IPCC 1995, 2001), the UV component of (sun)light was not considered (Seiler and Giehl 1977; Seiler et al., 1978). In studies of photochemically induced release of $\mathrm{CO}$ by dead plant material, it was demonstrated that the more energy-rich UV light had a very significant impact on the total CO emission (Tarr et al., 1995; Schade et al., 1999a; Derendorp et al., 2011). The aim of this study was thus to examine the potential of UVinduced $\mathrm{CO}$ emission from living plants in relation to plant species and environmental conditions. Experiments were carried out under controlled laboratory conditions and under in situ field conditions.

\section{Materials and methods}

\subsection{Plant material}

Leaves were freshly excised from well-watered plants grown in pots in the greenhouse (Brassica oleracea capitata $f$. alba, Ficus elastica, Zea mays), and from trees (Acer platanoides, Corylus avellana) and grasses growing in the vicinity of the laboratory (dominated by Deschampsia flexuosa and with minor occurrences of Achilla millefolium and Plantago lanceolata). Ecosystem analysis was focused on the grass vegetation that occurred on a sandy loam soil and received no fertilizer or other chemical treatment. 


\subsection{Measurement system}

Real-time measurements of [CO], corrected for $\mathrm{H}_{2} \mathrm{O}$ interference, were conducted by off-axis enhanced cavity spectroscopy (Los Gatos $\mathrm{N}_{2} \mathrm{O} / \mathrm{CO}$ analyzer, LGR Inc, Mountain View, CA, USA) connected to either an ecosystem Plexiglas chamber or a leaf scale Walz chamber (3010-GWK1, Heinz Walz GmbH, Effeltrich, Germany). We used the LGR in the low-flow configuration with a flow of $3.3 \mathrm{~L}$ per minute, $55 \mathrm{cc}$ per sec. The LGR internal volume was $411 \mathrm{cc}$. The Synflex tubing connecting the LGR to the chamber (Waltz or Plexiglas) was $6 \mathrm{~mm}$ outer diameter, $3 \mathrm{~mm}$ inner diameter, and the length was $3.20 \mathrm{~m}$ (inlet line plus outlet line total $6.20 \mathrm{~m}$ ).

\subsubsection{Natural grassland-atmosphere $\mathrm{CO}$ exchange}

Natural grassland-atmosphere $\mathrm{CO}$ exchange measurements were conducted under in situ conditions on natural vegetation and under ambient conditions, in September and October 2011 at DTU Ris $\varnothing$ campus $\left(55^{\circ} 41^{\prime} \mathrm{N}, 12^{\circ} 05^{\prime} \mathrm{E}\right)$ between 09:00 and 17:45. A UV-transparent Plexiglas chamber $\left(45 \times 45 \times 25 \mathrm{~cm}^{3}\right.$; PAR transmission $83 \%$; UV-B transmission $91 \%$ incl. water condensation on inside of chamber walls) was placed on a stainless steel collar pushed into the ground. A water-filled groove on top of the collar ensured a gas-tight seal between collar and chamber. The chamber was equipped with an internal fan to ensure mixing and thermocouples measuring air temperature. To exclude solar UV radiation in some experiments, a larger UVopaque chamber $\left(60 \times 60 \times 85 \mathrm{~cm}^{3}\right.$, transmitting only $32 \%$ UV-B, but $96 \%$ PAR) was placed around the grassland chamber. For measurements in the dark, the chamber was covered by light-excluding metal foil. Photosynthetic active radiation (PAR; 400-700 nm) and UV-B (280-315 nm) were measured at a horizontal plane next to the chamber with a LiCor LI-250A Light Meter and Gigahertz-Optik UV-1102 detector, respectively, and adjusted according to the abovementioned transmittance. This transmittance was verified after each measurement of gas exchange. The average temperature increase in the chamber was $2.98^{\circ} \mathrm{C}$, with a standard error of $1.29^{\circ} \mathrm{C}$ during measurements. Blank chamber emissions of $\mathrm{CO}$ were examined by placing the chamber over an inert surface (PTFE foil) under different light regimes. The analysis revealed no detectable $\mathrm{CO}$ emissions from the chamber itself.

\subsubsection{Exchange of $\mathrm{CO}$ by leaves}

A temperature-controlled and well-mixed Walz leaf chamber with a UV-transparent quartz glass lid was used for leaf measurements. For light- and UV-exposure experiments, the lid was fitted with varying sizes of apertures to ensure that only the sample of interest inside the chamber received light. For sun exposure, the chamber was placed on a table outside the lab. For artificial UV exposure, lamps were positioned at varying distances from the lid of the chamber in the lab (see Bruhn et al., 2009). For dark measurements the entire lid was covered with layers of black cloth. A UV-opaque filter (transmitting only $17 \%$ of UV-B, but $91 \%$ of PAR) was used to examine the UV effect. Both PAR and UV-B (280$315 \mathrm{~nm}$ ) were measured next to the chamber and adjusted as described in Sect. 2.2.1. The Walz chamber release of $\mathrm{CO}$ was characterized in the laboratory in relation to chamber temperature $(T)$ as $0.15 \times 10^{-6} \times \mathrm{e}^{0.05 T} \mathrm{nmol} \mathrm{CO} \mathrm{m}^{-2} \mathrm{~h}^{-1}$, and this value was subtracted from all calculations of $\mathrm{CO}$ emission rates. Exposed leaf areas were ca. 100 to $225 \mathrm{~cm}^{2}$.

\subsubsection{Calculation of exchange rates}

The exchange of $\mathrm{CO}$ between the surface and atmosphere was calculated based on the changes in chamber $\mathrm{CO}$ concentration over time. A steady $\mathrm{CO}$ concentration change was commonly observed $\left(R^{2}>0.95\right)$ within time windows lasting a minimum of 5-15 min, and rates were derived from linear regressions. Thus, the rate is derived from the observed slope and the treatment effects derived from the change in slopes. For the grass field: the full sun gross rate was calculated by subtracting the rate measured in full sun rate from the rate measured dark, and the UV-induced gross rate was calculated by subtracting the rate measured in full sun from the measured rate when UV-B was excluded.

\section{Results and discussion}

\subsection{Natural grass field-atmosphere CO exchange}

\subsubsection{Darkness}

Under dark conditions, the natural grass field was a significant sink for atmospheric $\mathrm{CO}$ $\left(-2819 \pm 210 \mathrm{nmol} \mathrm{CO} \mathrm{m}^{-2} \mathrm{~h}^{-1}, \quad\right.$ mean $\pm \mathrm{SE}, \quad n=24$, Fig. 1a). The measured uptake rate of $\mathrm{CO}$ in the dark can be approximated as the product of the CO diffusion coefficient of the topsoil and the $\mathrm{CO}$ concentration profile in the topsoil profile (Potter et al., 1996) according to Fick's first law. Therefore, CO uptake in the grass field is in agreement with the expectation of an active microbial community in the grass field oxidizing the CO (Potter et al., 1996; King and Weber, 2007).

\subsubsection{Natural sunlight}

In response to natural sunlight, the grassland exhibited a net CO release of $1281 \pm 259$ (mean \pm SE, $n=37$, measurements in four plots) $n m o l \mathrm{CO} \mathrm{m}^{-2} \mathrm{~h}^{-1}$ (Fig. 1a). The photo-induced gross release rate of $\mathrm{CO}$, $4099 \pm 334 \mathrm{nmol} \mathrm{CO} \mathrm{m}^{-2} \mathrm{~h}^{-1}$ for the grassland (Fig. 1b), was calculated as the difference between the rates measured in natural sunlight and the rate in darkness. 


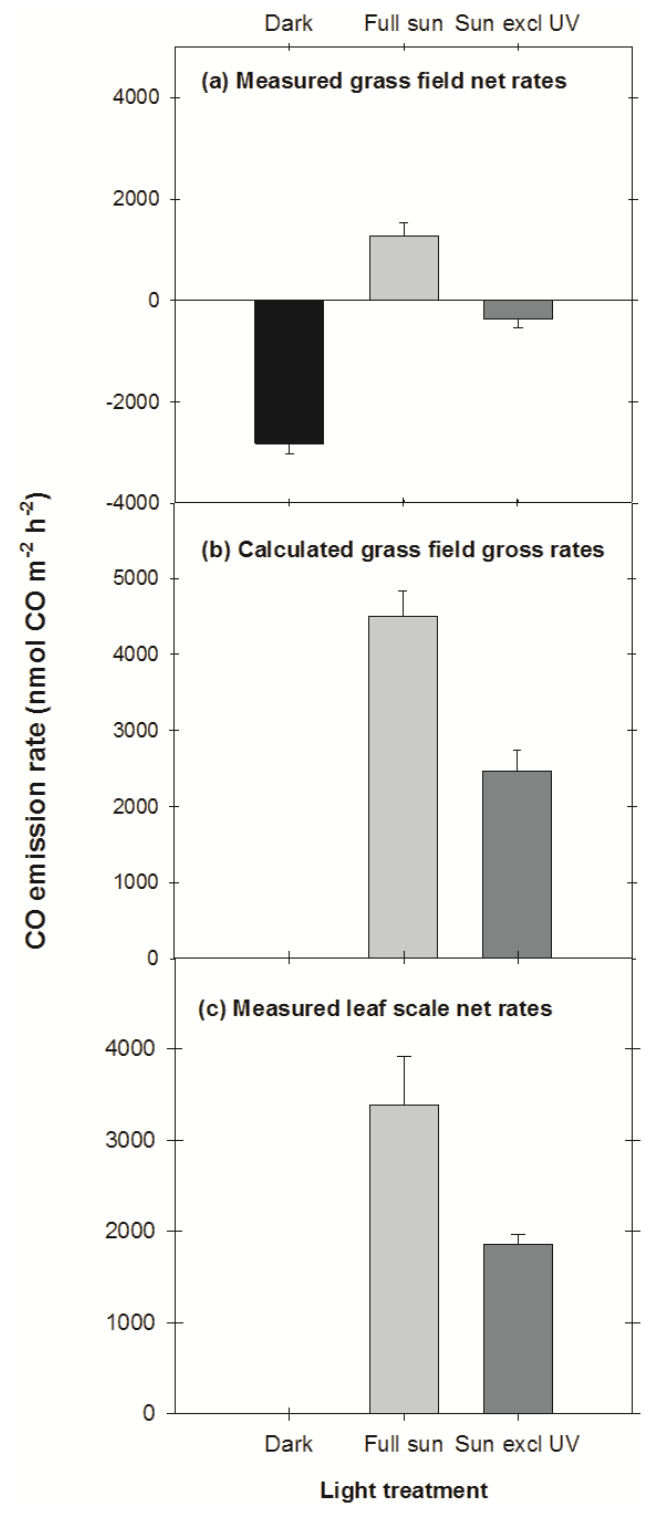

Fig. 1. (a) Measured natural grass field net $\mathrm{CO}$ emission rates in dark, sunlight and UV-excluded sunlight. Measurements were conducted with a Plexiglas chamber at ambient temperature (grass field $\left.\left[T=21.38^{\circ} \mathrm{C} ; n=22\right]\right)$. Values shown are means \pm S.E. The order of treatments (dark, full sunlight and sun screened for UV) was alternated between replicates. For the Plexiglas grass field chamber measurements the mean $( \pm$ S.E.) level of UV-B (280$315 \mathrm{~nm}$ ) was $0.50 \pm 0.01 \mathrm{Wm}^{-2}$ and the mean ( \pm S.E.) PAR was $711 \pm$ s.e. $16 \mu \mathrm{mol}$ photons $\mathrm{m}^{-2} \mathrm{~s}^{-1}$. (b) Calculated ecosystem gross rates of $\mathrm{CO}$ emission. (c) $\mathrm{CO}$ emission rates (mean \pm S.E., $n=4$ ) of leaves cut from the natural grass field. Measurements were conducted with a temperature-controlled chamber at $25^{\circ} \mathrm{C}$. The order of treatments (full sun and sun screened for UV) was alternated between replicates. For the temperature-controlled chamber measurements the mean ( \pm S.E.) level of UV-B $(280-315 \mathrm{~nm})$ was $0.51 \pm 0.03 \mathrm{Wm}^{-2}$ and the mean $( \pm$ s.e.) PAR was $789 \pm$ S.E. $47 \mu$ mol photons $\mathrm{m}^{-2} \mathrm{~s}^{-1}$.
This photo-induced release of $\mathrm{CO}$ from the grassland very likely has its origin in the living vegetation. Firstly, the ground was fully covered with green leaves of grassland species, and the soil was not exposed to light. Secondly, the estimated release of $\mathrm{CO}$ from the natural grass field is similar to that of excised grass leaves from the grass field (Fig. 1c, Sect. 3.2). To date no other study has explicitly examined the potential of $\mathrm{CO}$ emission from living vegetation in response to the full natural spectrum of sunlight. However, a recent study by Galbally et al. (2010) of soil-atmosphere CO exchange in a semiarid Eucalyptus sp. ecosystem was conducted with chambers exposed to natural sunlight, although neither the transparent chamber area nor potential discrimination of certain wavelengths was clearly specified. In that study Galbally et al. reported CO release (net) rates of ca. $3000 \mathrm{nmol} \mathrm{CO} \mathrm{m}^{-2} \mathrm{~h}^{-1}$ in the Eucalyptus sp. ecosystem, in the same range as the gross rate estimated for the grassland studied here. Even though the authors ascribe the $\mathrm{CO}$ release to have predominantly originated in the organic soil and plant litter (Eucalyptus sp.), it is noteworthy that the Eucalyptus sp. ecosystem had a $50 \%$ leaf cover, and furthermore the ground was covered with lichens and mosses. Thus, it may be speculated that a substantial part of the measured $\mathrm{CO}$ emission in the Eucalyptus sp. ecosystem in response to natural sunlight may have originated from living vegetation rather than plant litter.

\subsubsection{Effects of UV}

The effects of natural UV irradiance on gross $\mathrm{CO}$ emission rates were tested under field conditions by shielding the measurement chamber with an almost completely UVopaque chamber with little effect on total PAR transmission (Fig. 1a). In response to this, the gross CO emission rates were approximately halved for the natural grass field to $2466 \pm 273 \mathrm{nmol} \mathrm{CO} \mathrm{m}^{-2} \mathrm{~h}^{-1}$ (Fig. 1b).

As the UV-opaque field chamber transmitted $32 \% \mathrm{UV}$ $\mathrm{B}$, the $\mathrm{CO}$ emission from the natural grass field in response to natural solar PAR only was estimated by calculating the value at $0 \% \mathrm{UV}$ from a linear extrapolation of the relationship between the data points (100\% PAR and $32 \% \mathrm{UV}$, $2466 \pm 273 \mathrm{nmol} \mathrm{CO} \mathrm{m}^{-2} \mathrm{~h}^{-1}$, and $100 \%$ PAR and $100 \%$ $\mathrm{UV}, 4099 \pm 334 \mathrm{nmol} \mathrm{CO} \mathrm{m}^{-2} \mathrm{~h}^{-1}$ ). This resulted in a value of $1697 \mathrm{nmol} \mathrm{CO} \mathrm{m}^{-2} \mathrm{~h}^{-1}$. Interestingly, this value is very similar to the value of $1467 \mathrm{nmol} \mathrm{CO} \mathrm{m}^{-2} \mathrm{~h}^{-1}$ measured in Brassica oleracea capitata $f$. alba leaves in response to $789 \mu$ mol photons $\mathrm{m}^{-2} \mathrm{~s}^{-1}$ artificial PAR in the laboratory (data not shown; $789 \mu$ mol photons $\mathrm{m}^{-2} \mathrm{~s}^{-1}$; PAR was the mean level during field measurements).

The actual value of $\mathrm{CO}$ emission from the natural grass field in response to natural solar UV radiation can thus be calculated as $4099 \mathrm{nmolCO} \mathrm{m}^{-2} \mathrm{~h}^{-1}$ minus $\quad 1697 \mathrm{nmolCO} \mathrm{m}^{-2} \mathrm{~h}^{-1}$, resulting in $2402 \mathrm{nmol} \mathrm{CO} \mathrm{m}^{-2} \mathrm{~h}^{-1}$. 


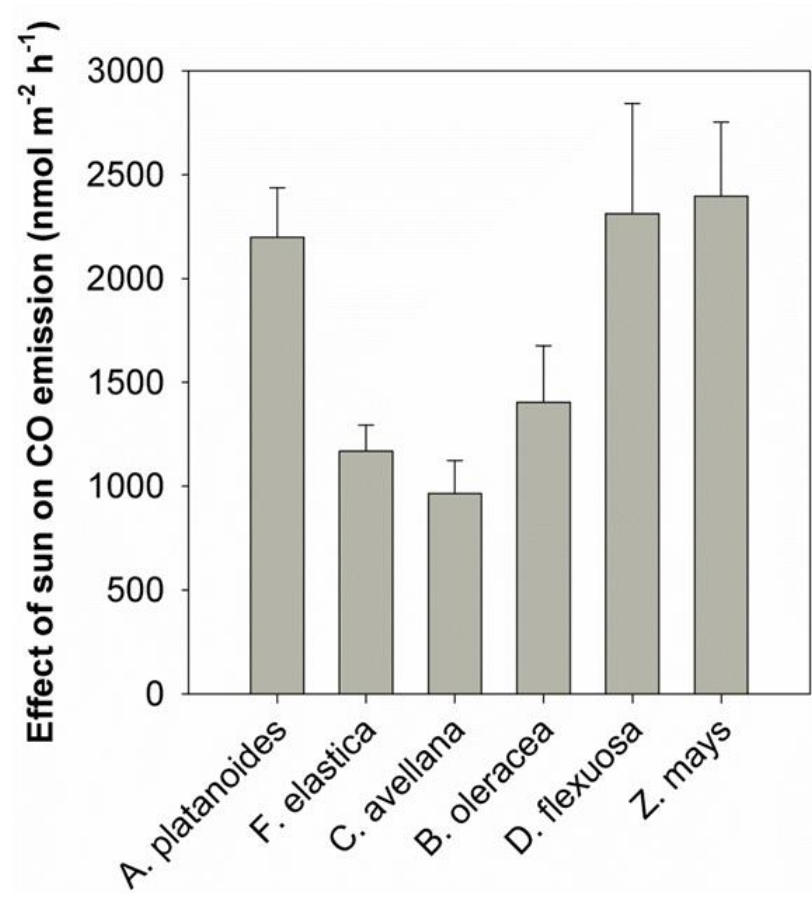

Fig. 2. The effect of solar radiation on the $\mathrm{CO}$ emission rates (ER) by leaves (mean \pm S.E. of $\mathrm{ER}_{\text {light }}-\mathrm{ER}_{\text {dark }}$ ). Measurements were conducted with a temperature-controlled chamber at $25^{\circ} \mathrm{C}$. The order of treatments (full sun and dark) was alternated between replicates. For the temperature-controlled chamber measurements the mean ( \pm S.E.) level of UV-B (280-315 nm) was $0.51 \pm 0.03 \mathrm{Wm}^{-2}$ and the mean ( \pm s.e.) PAR was $789 \pm$ E.E. $47 \mu$ mol photons $\mathrm{m}^{-2} \mathrm{~s}^{-1}$.

A study by Tarr et al. (1995) on the effect of artificial light on $\mathrm{CO}$ production by leaf litter indicated that UV-irradiation was a stronger catalyst than visible light. A similar response has been reported for photo-induced carbon dioxide production in terrestrial plant litter (Brandt et al., 2009).

\subsection{Leaf-atmosphere $\mathrm{CO}$ exchange}

\subsubsection{Natural sunlight}

Freshly excised green leaves of six different plant species exhibited rates of net (i.e. after subtracting rates from dark measurements) $\mathrm{CO}$ release ranging from 965 to $2396 \mathrm{nmol} \mathrm{CO} \mathrm{m}^{-2} \mathrm{~h}^{-1}$ (mean $1740 \mathrm{nmol} \mathrm{CO} \mathrm{m}^{-2} \mathrm{~h}^{-1}$ ) when exposed to natural sunlight (Fig. 2). These rates are of the same magnitude as the gross rates (i.e. incl. dark rates) reported by Tarr et al. (1995) by green leaves, $1800 \mathrm{nmol} \mathrm{CO} \mathrm{m}^{-2} \mathrm{~h}^{-1}$ in response to simulated sunlight $\left(650 \mathrm{Wm}^{-2} \mathrm{UV}-\mathrm{B}+\mathrm{UV}-\mathrm{A}+\mathrm{PAR}\right)$, and those by Yonemura et al. (1999) by green leaves, 1300 to $1550 \mathrm{nmol} \mathrm{CO} \mathrm{m}^{-2} \mathrm{~h}^{-1}$ in response to $490 \mathrm{Wm}^{-2} \mathrm{PAR}$ (without UV). In comparison, Seiler et al. (1978) reported a mean photo-induced CO pro-

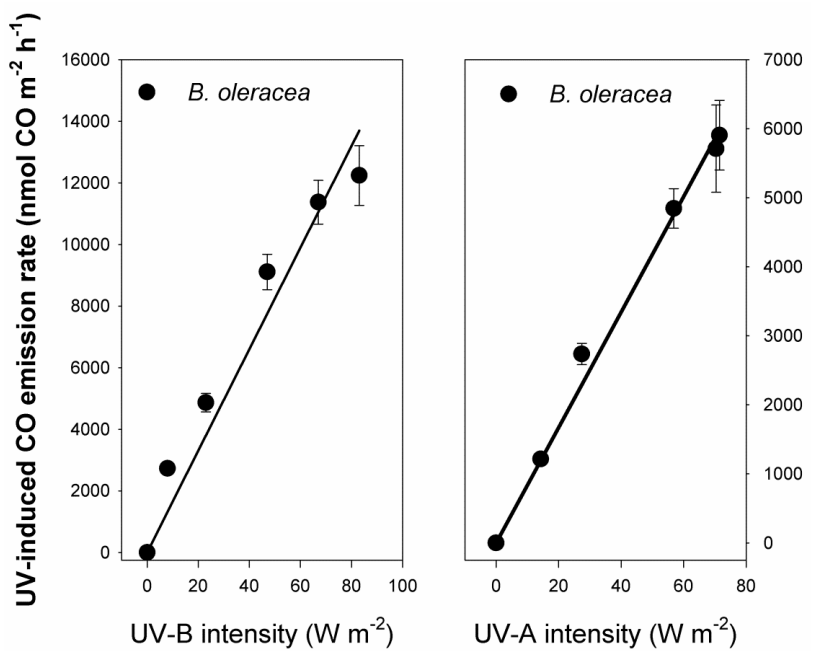

Fig. 3. The UV-irradiance response of $\mathrm{CO}$ emissions by leaf (mean \pm S.E. of $\mathrm{ER}_{\text {light }}-\mathrm{ER}_{\text {dark }}$ ) at $25^{\circ} \mathrm{C}$. The lines indicate the position of the linear regression lines intercepting at $(0,0)$ and slopes of 160 and 89 for B. oleracea (UV-B) and B. oleracea (UVA), respectively. The regression coefficients $\left(R^{2}\right)$ are 0.96 and 0.98 , respectively.

duction by living plants of $386 \mathrm{nmol} \mathrm{m}^{-2} \mathrm{~h}^{-1}$ in response to $50 \mathrm{Wm}^{-2}$ PAR (without UV).

Photo-induced $\mathrm{CO}$ emissions from leaf litter are typically 5 to 10 times higher than from living plants (Tarr et al., 1995; Schade et al., 1999a; Yonemura et al., 1999).

\subsubsection{Effects of UV}

Rates of $\mathrm{CO}$ emission by green leaves increased near-linearly with increasing intensity of UV-B and UV-A (Fig. 3). Such linear irradiance responses have been previously reported for Vicia faba and Platanus acerfolia (Seiler and Giehl, 1977), Oryza sativa (Yonemura et al., 1999), and Sequoiadendron gigantum (Derendorp et al., 2011).

The $\mathrm{CO}$ emission at specific irradiance intensities increased with decreasing wavelength of the radiation, as illustrated by the greater response in $\mathrm{CO}$ emissions under UV-B compared to UV-A (compare slopes in Fig. 3). Similar results have been found for leaf litter (Tarr et al., 1995; Schade et al., 1999a).

Schade et al. (1999b) suggested cellulose to be the main precursor for UV radiance-induced $\mathrm{CO}$ emission from dried leaf matter. Cellulose was recently also found to emit $\mathrm{CH}_{4}$ in response to UV radiance; however, only at much lower rates compared to that of other structural components (Vigano et al., 2008). The exact nature of the origin of the produced $\mathrm{CO}$ in fresh leaves remains unclear, but it may be cellulose. UV-induced emission rates of $\mathrm{CO}$ from dead plant material have been observed to be oxygen dependent in several studies (Tarr et al., 1995; Yonemura et al., 1999; Derendorp et al., 2011). In studies on green lima bean leaves, Tarr et al. (1995) 


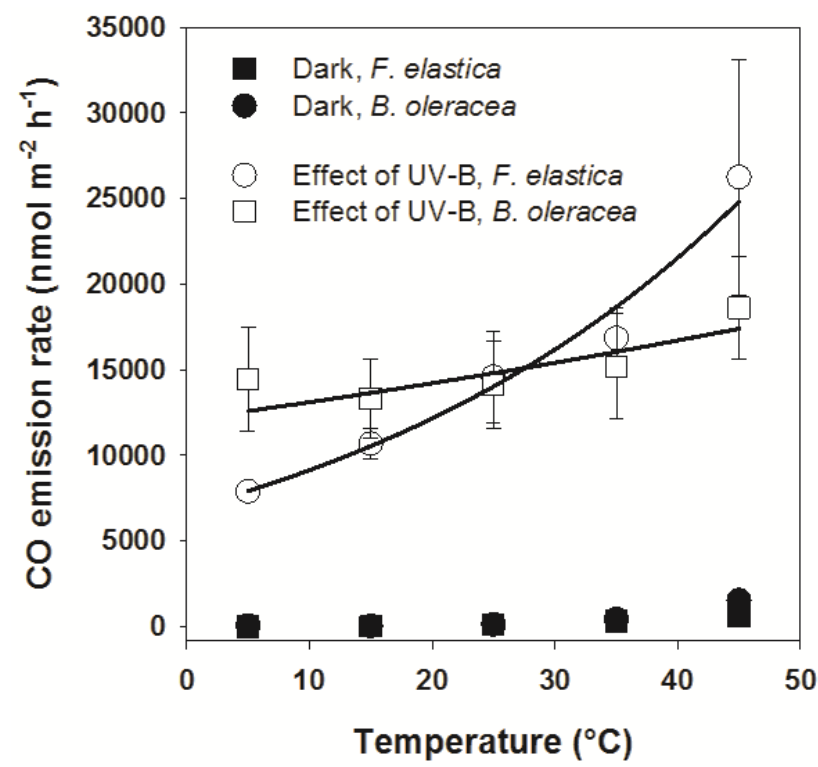

Fig. 4. Temperature dependence of UV-induced $\mathrm{CO}$ emission rate (ER) by leaf $\left(\mathrm{ER}_{\text {light }}-\mathrm{ER}_{\text {dark }}\right)$ and dark $\mathrm{CO}$ emission rate (mean \pm S.E.). The full lines represent exponential regression to data for leaves. See Sect. 3.2.3 for equation coefficients.

indicated that the photo-production of $\mathrm{CO}$ occurred inside the leaves. However, this could not be confirmed by Yonemura et al. (1999).

We suggest that the process per se may be photolysis, and therefore the extrapolation of UV effects would only be compromised by a change in the source. This has important implications for future up-scaling.

We did not test the effects of a directly measured water status. However, we did measure the $\mathrm{CO}$ emission of dried material (litter), and found, as others (Tarr et al., 1995; Yonemura et al., 1999; Derendorp et al., 2011), that the CO emission is about one order of magnitude larger in dried leaves compared to that of fresh leaves. Hence, more knowledge is also needed in order to evaluate how a higher degree of leaf desiccation may increase rates of $\mathrm{CO}$ emission. Schade et al. (1999b) speculated that during senescence and leaf death, the colouring changes to darker leaf colours cause a greater degree of light absorption, which may explain higher rates of UV radiance-induced $\mathrm{CO}$ emission from dried leaf matter.

\subsubsection{Effects of temperature}

The effect of temperature $(T)$ on the $\mathrm{CO}$ emission rate, $\mathrm{ER}$, can be described by the exponential function $E R(T)=$ $\alpha e^{\beta T}$ (Fig. 4). Under UV-B, F. elastica exhibited a temperature response of the $\mathrm{UV}$-induced $\left(\mathrm{ER}_{\mathrm{UV}}\right.$ minus $\left.\mathrm{ER}_{\mathrm{dark}}\right) \mathrm{CO}$ emission with $\alpha=6861 \mathrm{nmol} \mathrm{CO} \mathrm{m}^{-2} \mathrm{~h}^{-1}$ and a temperature sensitivity $\beta=0.029$. In contrast, $B$. oleracea exhibited a temperature response of the UV-induced (ER $\mathrm{EV}_{\mathrm{U}}$ minus $\mathrm{ER}_{\text {dark }}$ ) CO emission with $\alpha=12087 \mathrm{nmol} \mathrm{CO} \mathrm{m}^{-2} \mathrm{~h}^{-1}$ and a temperature sensitivity $\beta=0.008$. In darkness, the mean temperature response of the emission of the two plant species resulted in $\alpha=11 \mathrm{nmol} \mathrm{CO} \mathrm{m}^{-2} \mathrm{~h}^{-1}$ and a temperature sensitivity $\beta=0.104$. Thus, the mean temperature sensitivity under UV-B is so low that it indicates an abiotic process (Derendorp et al., 2011). In darkness, however, the temperature sensitivity for the green leaves resembled the activation energy associated with biological processes.

\subsection{Relevance of measured rates}

The global net burden of CO is $360 \mathrm{Tg} \mathrm{CO} \mathrm{yr}^{-1}$ (IPCC 2001). Photo-induced $\mathrm{CO}$ emission from living plants has long been recognized and has been estimated to contribute globally with 50-200 $\mathrm{Tg} \mathrm{CO} \mathrm{yr}^{-1}$ (cf. Tarr et al., 1995). Importantly, though, this global estimate is not taken into account by the IPCC (IPCC, 2001). Further, this estimate is based solely on studies regarding the visible part $(400-700 \mathrm{~nm})$ of the solar spectrum, as the potential effects of light with shorter wavelengths were not examined in the underlying experimental studies (Seiler and Giehl, 1977; Seiler et al., 1978). Therefore, we still await a proper global estimate of UV radianceinduced $\mathrm{CO}$ emission by living vegetation. Our study provides the first in situ measurements at ambient conditions of ecosystem $\mathrm{CO}$ emission by living plants in response to natural solar UV irradiation. Importantly, we found that in the studied natural grass field the photo-induced $\mathrm{CO}$ emission due to natural solar UV radiation is more than half of the value of that due to the total solar spectrum at the Earth's surface. This may imply that the previous global estimate of photo-induced $\mathrm{CO}$ emission from living plants of 50 $200 \mathrm{Tg} \mathrm{CO} \mathrm{yr}^{-1}$ (cf. Tarr et al., 1995) should perhaps be doubled. Thus, future global budgets need to include $\mathrm{CO}$ emission caused by natural UV irradiance.

We do propose that future global estimates may be possible based on the results presented in the current paper. The number of plant species tested was limited, but we do not consider this a major concern, given the relatively low variation between species in $\mathrm{CO}$ emission rates under UV (Fig. 2). A more variable selection of test species with an even greater variability in leaf surface characteristics may be needed to confirm this. This would also allow for further testing of our finding that the $\mathrm{CO}$ emissions from excised leaves are similar to those from attached leaves. In this context it is noteworthy that the current global scale numbers for $\mathrm{CO}$ adopted by the IPCC are derived from fewer plant species (Seiler et al., 1978; see Tarr et al., 1995 for discussion) than used in the current study. For future chamber measurements addressing $\mathrm{CO}$ exchange in situ it is important to use UV-transparent materials when constructing chambers.

It is possible that the otherwise natural breakdown of trace gasses by $\mathrm{UV}$ radiation in the presence of $\mathrm{OH}$ radicals is partially or completely unnoticed in a laboratory scale setup as used in the current study. The lifetime of $\mathrm{OH}$ radicals in the atmosphere is less than one second (Isaksen and Dalsøren, 
2011), whereas potential formation rates under the current experimental conditions are unknown. Importantly, though, $\mathrm{CO}$ depletion by radicals is already a known sink and thus already accounted for (IPCC, 2001).

Acknowledgements. We wish to thank Vincent Gauci and Michael Peacock for reading the manuscript and suggesting improvements.

Edited by: M. Bahn

\section{References}

Brandt, L. A., Bohnet, C., and King, J. Y.: Photochemically induced carbon dioxide production as a mechanism for carbon loss from plant litter in arid ecosystems, J. Geophys. Res., 114, G02004, doi:10.1029/2008JG000772, 2009.

Bruhn, D., Mikkelsen, T. N., Øbro, J., Willats, W. G. T., and Ambus, P.: Effects of temperature, ultraviolet radiation and pectin methyl esterase on aerobic methane release from plant material, Plant Biol., 11, 43-48, doi:10.1111/j.1438-8677.2009.00202.x, 2009.

Derendorp, L., Quist, J. B, Holzinger, R., and Röckmann, T.: Emissisions of $\mathrm{H}_{2}$ and $\mathrm{CO}$ from leaf litter of $\mathrm{Se}$ quoiadendron giganteum and their dependence on UV radiation and temperature, Atmos Environ., 45, 7520-7524, doi:10.1016/j.atmosenv.2011.09.044, 2011.

Galbally, I., Meyer, C. P., Wang, Y.-P., and Kirstine, W.: Soilatmosphere exchange of $\mathrm{CH}_{4}, \mathrm{CO}, \mathrm{N}_{2} \mathrm{O}$ and $\mathrm{NO}_{\mathrm{x}}$ nd the effects of land-use change in the semiarid Mallee system in Southeastern Australia, Global Change Biol., 16, 2407-2419, doi:10.1111/j.1365-2486.2010.02161.x, 2010.

Guenther, A.: The contribution of reactive carbon emissions from vegetation to the carbon balance of terrestrial ecosystems, Chemosphere, 49, 837-844, doi:10.1016/S00456535(02)00384-3, 2002

IPCC: Radiative Forcing of Climate Change, Ch 2. Climate Change 1995, The Science of Climate Change, Contribution of WGI to the Second Assessment Report of the Intergovernmental Panel on Climate Change, edited by: Schimel, D., Alves, D., Enting, I., Heimann, M., Joos, R., Raynaud, D., Wigley, T., Prather, M., Derwent, R., Ehhalt, D., Eraser, R., Sanhueza, E., Zhou, X., Jonas, R., Charlson, R., Rodhe, H., Sadasivan, S., Shine, K. R., Fouquart, Y., Ramaswamy, V., Solomon, S., Srinivasan, J., Albritton, D., Derwent, Isaksen, L., Lal, M., Wuebbles, D., Cambridge University Press, Cambridge, United Kingdom and New York, NY, USA, 51-64, 1995.
IPCC: Climate Change 2001: The Scientific Basis, Contribution of Working Group I to the Third Assessment Report of the Intergovernmental Panel on Climate Change, edited by: Houghton, J. T., Ding, Y., Griggs, D. J., Noguer, M., van der Linden, P. J., Dai, X., Maskell, K., and Johnson, C. A., Cambridge University Press, Cambridge, United Kingdom and New York, NY, USA, 881 pp, 2001.

Isaksen, I. S. A. and Dalsøren, S. B.: Getting a better estimate of an atmospheric radical, Science, 331, 38-39, 2011.

King, G. M. and Weber, C. F.: Distribution, diversity and ecology of aerobic CO-oxidizing bacteria, Nat. Rev. Microbiol., 5, 107-118, 2007.

Potter, C. S., Klooster, S. A., and Chatfield, R. B.: Consumption and production of carbon monoxide in soils: a global model analysis of spatial and seasonal variation, Chemosphere, 33, 1175-1193, 1996.

Schade, G. W., Hofmann, R.-F., and Crutzen, P. J.: CO emissions from degrading plant matter, (I) Measurements, Tellus B, 51, 889-908, 1999a.

Schade, G. W. and Crutzen, P. J.: CO emissions from degrading plant matter (II), Estimate of a global source strength, Tellus B, 51, 909-918, 1999b.

Seiler, W. and Giehl, H.: Influence of plants on the atmospheric carbon monoxide, Geophys. Res. Lett., 8, 329-332, 1977.

Seiler, W., Giehl, H., and Bunse, G.: The influence of plants on atmospheric carbon monoxide and dinitrogen oxide, Pure Appl. Geophys., 116, 439-451, 1978.

Tarr, M. A., Miller, W. L., and Zapp, R. G.: Direct carbon monoxide photoproduction from plant matter, J. Geophys. Res., 100, 11403-11413, 1995.

Yonemura, S., Morokuma, M., Kawashima, S., and Tsuruta, H.: Carbon monoxide photoproduction from rice and maize leaves, Atmos. Environ., 33, 2915-2920, 1999. 